\title{
Nasopharyngeal Angiofibroma
}

National Cancer Institute

\section{Source}

National Cancer Institute. Nasopharyngeal Angiofibroma. NCI Thesaurus. Code C27479.

A morphologic variant of fibroma arising from the nasopharynx. It is characterized by the presence of numerous dilated vascular channels. 